\title{
Reduction of leaf photosynthesis and transpiration rates of potato plants by second-stage juvenilles of Globodera pallida
}

\author{
J. SCHANS* Departments of Nematology and Theoretical Production Ecology, P.O. Box 8123, 6700 ES \\ Wageningen, The Netherlands
}

Received 23 November 1990; received in revised form 11 February 1991; accepted for publication 18 February 1991

\begin{abstract}
Net photosynthesis and transpiration rates of potato plants, grown in pots in the greenhouse, were measured at various light irradiances and ambient $\mathrm{CO}_{2}$ concentrations, $3 \mathrm{~d}$ after inoculation with second stage juveniles of Globodera pallida. Gas exchange rates, both in darkness and in light, and the initial light use efficiency were strongly reduced by nematodes. Stomatal conductance of infected plants was lower than that of control plants and showed little response to decreasing ambient $\mathrm{CO}_{2}$ concentration. The maximum internal $\mathrm{CO}_{2}$ concentration of infected plants was lower than that of control plants. Globodera pallida reduced photosynthesis also by apparent non-stomatal effects.

The effects of $G$. pallida on gas exchange rates are similar to the effects of abscisic acid in the transpiration stream and of abiotic stresses in the root environment. Apparently, there is a general response of plant roots to adverse conditions. The reduction of photosynthesis may be an important factor in yield reduction by potato cyst nematodes.
\end{abstract}

Key-words: Solanum tuberosum L.; Globodera pallida Stone; potato cyst nematodes; plant-parasite interaction; gas exchange; stomata; water-use efficiency

\section{Introduction}

Potato cyst nematodes (PCN), Globodera rostochiensis (Woll.) Skarbilovich and G. pallida Stone, cause serious yield losses in regions where potatoes are grown frequently. Empirical relations between PCN density and yield loss, averaged over several experiments, have been established by Seinhorst (1965) and Brown (1969). The parameter values in these relations vary strongly among years, locations and cultivars (e.g. Greco et al., 1982; Seinhorst, 1982; Brown, 1983). This variation may be due to effects of variable environmental factors on the physiological processes that determine the behaviour of the potato - PCN system. These effects are not described by the Seinhorst or the Brown equations.

Understanding of the effects of PCN on the physiological processes which determine the growth rate of a potato crop (e.g. photosynthesis, respiration and assimilate partitioning) is a prerequisite for explanation of the

Correspondence and present address: J. Schans, Centre for Agrobiological Researeh (CABO), P. . BOx 14,6700 AA Wageningen, The Netherlands. variation in yield reduction by $\mathrm{PCN}$ under field conditions. Several studies have been focused on effects of PCN on weight, dry matter content and mineral composition of plant organs and on plant water relations (reviewed by Trudgill, 1986). However, various disorders can cause the observed phenomena and the experiments do not explain which plant physiological processes are affected by PCN.

Disturbance of potato growth processes by PCN may occur during several phases of nematode development, in particular the invasion of roots by second-stage juveniles and the withdrawal of plant metabolites by following nematode stages. In this paper, the effects of penetration into roots and subsequent formation of syncytia by second stage juveniles of $G$. pallida on photosynthesis and transpiration rates of potato plants are investigated.

\section{Materials and methods}

Two experiments are described: one using the cultivar 'Irene' (susceptible) and nematode densities of 0 and 15 juveniles per gram of soil; and one using the cultivar 'Darwina' (with PCN resistance derived from Solanum vernei) and nematode densities of 0 and 65 juveniles per gram of soil.

\section{Plants, nematodes and inoculation}

Tubers (size: $28-35 \mathrm{~mm}$, with one sprout) of potato cultivars 'Irene' and 'Darwina' were surface-sterilized in a hypochlorite solution and planted in pots containing $4 \mathrm{~kg}$ of fertilized sandy loam soil to which $15 \%$ by weight of water was added $(\mathrm{pF}=2$; approximately field capacity). The pots were weighed and watered twice a day to keep soil moisture close to this level. The plants were grown in the glasshouse with 16 -h daylength. The minimum temperature was $14^{\circ} \mathrm{C}$ and the maximum varied between 20 and $26^{\circ} \mathrm{C}$.

Cysts of $G$. pallida pathotype $\mathrm{Pa} 2$ were placed in root exudate solution at $20^{\circ} \mathrm{C}$ after being soaked in water for $5 \mathrm{~d}$. The root exudate solution was changed each day and the emerged second-stage juveniles were collected and stored at $5^{\circ} \mathrm{C}$. Hatching continued over a period of $10 \mathrm{~d}$. Plants were inoculated 3 weeks after emergence. A suspension of the juveniles was injected into the soil using a veterinary syringe to approximate an even 


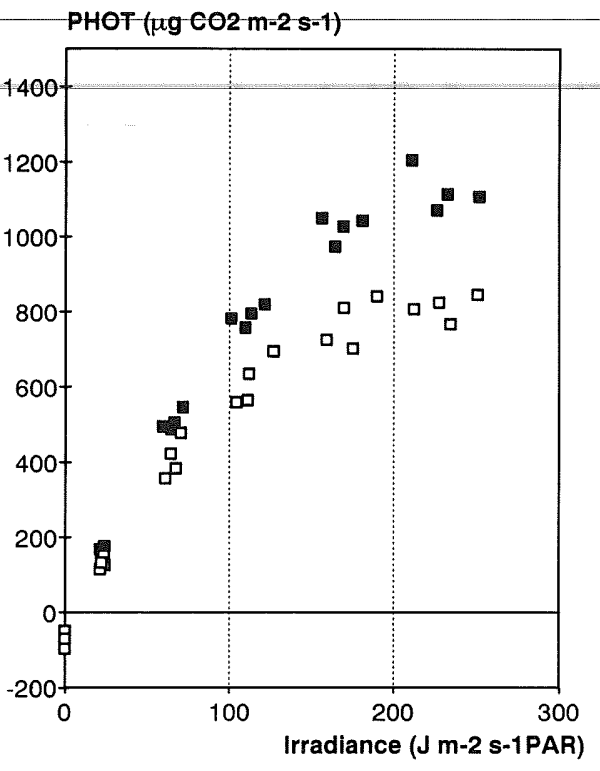

Figure 1. Response of net photosynthesis rate (PHOT; $\mu \mathrm{g} \mathrm{m}^{-2} \mathrm{~s}^{-1}$ ) of leaves of potato cultivar 'Irene' to irradiance $\left(\mathrm{J} \mathrm{m}^{-2} \mathrm{~s}^{-1}\right), 3 \mathrm{~d}$ after inoculation with hatched juveniles of G. pallida ( 15 juveniles per gram of soil), and of leaves of control plants. Symbols: ( $\square$ ) G. pallida-infected plants; (圆) control plants.

vertical distribution of juveniles. Eight uniformly distributed injections per pot were made. The control plants were inoculated with water.

\section{Measurement of nematode density in roots}

Roots were carefully separated from the soil, air-dried on filter paper for $15 \mathrm{~h}$, after which fresh weight was determined. The roots of control plants and $75 \%$ (by fresh weight) of infected roots were placed at $80^{\circ} \mathrm{C}$ for $3 \mathrm{~d}$ to determine dry weight. The remaining $25 \%$ (by fresh weight) of the infected roots were used to estimate the number of penetrated juveniles. The roots were macerated with a blender. The suspension was poured over three sieves $(350,175$ and $45 \mu \mathrm{m})$. The debris from the $45 \mu \mathrm{m}$ and $175 \mu \mathrm{m}$ sieves were collected separately and each was suspended in $80 \mathrm{~cm}^{3}$. From each suspension, two $5 \mathrm{~cm}^{3}$ samples were taken and stained with acid fuchsin. The nematodes present were counted. The debris from the $350 \mu \mathrm{m}$ sieve was macerated again and the procedure was repeated to collect remaining nematodes. This appeared sufficient to collect all nematodes.

\section{Gas exchange measurements}

Three days after inoculation, rates of photosynthesis and transpiration were measured on the fifth leaf from the top. Leaves were counted starting from the first leaf with terminal leaflet $>1 \mathrm{~cm}^{2}$. The laboratory assembly used is similar to the type described by Louwerse \& van Oorschot (1969). The $\mathrm{CO}_{2}$ concentration and water vapour content of the air stream entering and leaving the leaf chamber, irradiance, temperature and air humidity were recorded by a micro-computer. From these data, net photosynthesis and transpiration rates, stomatal resistance and internal $\mathrm{CO}_{2}$ concentrations were calculated. For both cultivars, the light response of gas exchange rates at a constant ambient $\mathrm{CO}_{2}$-concentration of $620 \mathrm{mg} \mathrm{m}^{-3}$ was measured at irradiances ranging from 0 to $250 \mathrm{~J} \mathrm{~m}^{-2} \mathrm{~s}^{-1}$ (photosynthetically active radiation, PAR). These measurements continued for $3-5 \mathrm{~h}$. The light response was characterized by three parameters: the net photosynthesis rate at high irradiance (PHOTHI, in $\mu \mathrm{g} \mathrm{CO}_{2} \mathrm{~m}^{-2} \mathrm{~s}^{-1}$ ), the respiration rate in the dark ( $\mathrm{RD}$, in $\mu \mathrm{g} \mathrm{CO}_{2} \mathrm{~m}^{-2} \mathrm{~s}^{-1}$ ), and the initial light use efficiency (EFF, in $\mu \mathrm{g} \mathrm{CO}_{2} \mathrm{~J}^{-1}$ ). Values of PHOTHI and $\mathrm{RD}$ were measured directly. Values of EFF were calculated as the increase in photosynthesis rate per unit of irradiance between darkness and the first light level. To separate between stomatal and non-stomatal effects on gas exchange (Rabbinge, Jorritsma \& Schans, 1985; Kropff, 1987), the $\mathrm{CO}_{2}$ response of gas exchange rates at a constant irradiance of $250 \mathrm{~J} \mathrm{~m}^{-2} \mathrm{~s}^{-1}$ (PAR) was measured for 'Darwina' at ambient $\mathrm{CO}_{2}$ concentrations ranging from $1600 \mathrm{mg} \mathrm{m}^{-3}$ at the beginning of the measurements to $80 \mathrm{mg} \mathrm{m}^{-3}$ at the end. These measurements, performed immediately after measuring the light response, lasted $4-5 \mathrm{~h}$. The $\mathrm{CO}_{2}$ response was characterized by the net photosynthesis rate at high ambient $\mathrm{CO}_{2}$ concentration (PHOTHC, in $\mu \mathrm{g} \mathrm{CO}_{2} \mathrm{~m}^{-2}$. $\mathrm{s}^{-1}$ ) and the initial slope of the $\mathrm{CO}_{2}$ slope response curve, i.e. the mesophyll conductance $\left(\mathrm{MC}\right.$, in $\left.\mathrm{mm} \mathrm{s}^{-1}\right)$. Values of PHOTHC were measured directly. As a criterion of $\mathrm{MC}$ the increase in photosynthesis rate per unit of $\mathrm{CO}_{2}$ concentration between the two lowest internal $\mathrm{CO}_{2}$ concentration levels was employed. In all

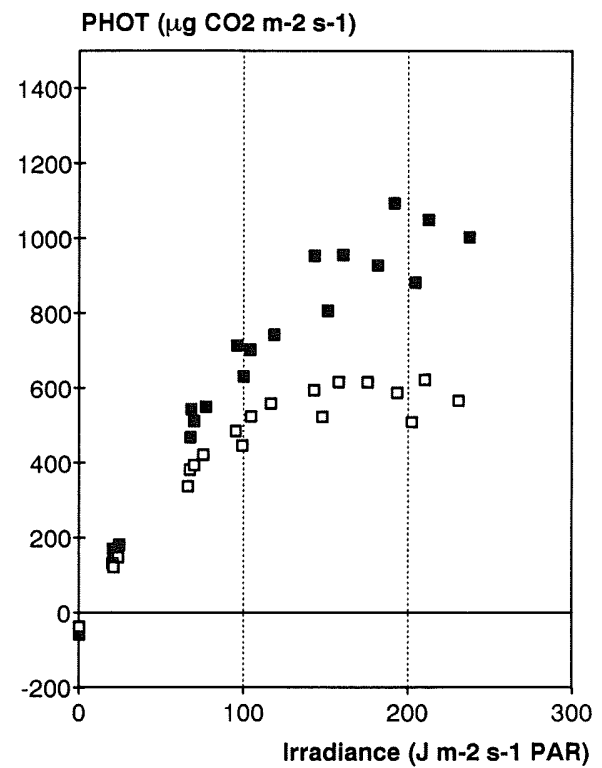

Figure 2. Response of net photosynthesis rate (PHOT; $\mu \mathrm{g} \mathrm{m}^{-2} \mathrm{~s}^{-1}$ ) of leaves of potato cultivar 'Darwina' to irradiance $\left(\mathrm{J} \mathrm{m}^{-2} \mathrm{~s}^{-1}\right), 3 \mathrm{~d}$ after inoculation with hatched juveniles of $G$. pallida ( 65 juveniles per gram of soil), and of leaves of control plants. Symbols: ( $\boxminus$ ) G. paltida-infected plants; (10 control plants. 
series, air temperature-was-approximately- $20^{\circ} \mathrm{C}$ and-air humidity was approximately $1 \mathrm{KPa}$. The area and fresh and dry weights of the measured leaves were recorded immediately after the gas exchange measurements.

Gas exchange rates of plant leaves are controlled by the relative opening of stomata. Stomatal opening may be affected directly by a stimulus, or indirectly as a reaction on changes in the carboxylation rate (Schulze, 1986). Accordingly, effects of $G$. pallida on gas exchange rates may be caused by direct and indirect effects on stomatal conductance. In darkness, carboxylation processes are absent, therefore an effect of $G$. pallida on $\mathrm{H}_{2} \mathrm{O}$ and $\mathrm{CO}_{2}$ exchange rates indicates a direct influence on stomatal conductance. An effect on $\mathrm{CO}_{2}$ exchange rate only would indicate an effect of $G$. pallida on the leaf respiration rate. When gas exchange rates of irradiated leaves are affected by $G$. pallida, then direct and indirect effects on stomata may be present simultaneously. Indirect effects can be demonstrated by measuring the $\mathrm{CO}_{2}$ response of gas exchange rates at constant high irradiance, under the assumption that the measured gas exchange is uniformly distributed over the leaf. Differences in stomatal resistance are eliminated by relating the photosynthesis rate to the internal $\mathrm{CO}_{2}$ concentration. The mesophyll conductance for $\mathrm{CO}_{2}$ can then be calculated. If this conductance is reduced by $G$. pallida, then indirect effects on stomatal opening must exist. However, if the distribution of transpiration and photosynthesis over the leaf is non-uniform (Downton, Loveys \& Grant, 1988), then indirect effects can not be distinguished.

\section{Results}

\section{Photosynthesis and transpiration measurements}

Dark respiration and transpiration rates (RD and TRANSD, respectively) of 'Darwina' plants infected with $G$. pallida were significantly lower than RD and TRANSD of 'Darwina' control plants (Table 1). This indicates that stomatal conductance was already reduced $3 \mathrm{~d}$ after inoculation with second stage juveniles of $G$. pallida. The dark respiration and transpiration rates of 'Irene' were not affected, probably because of the lower inoculum level used for this cultivar.
The light response-of the net photosynthesis rate for both cultivars with and without nematodes is presented in Figs 1 and 2. The initial light use efficiency (EFF, Table 1) of 'Darwina' plants was significantly reduced by $G$. pallida infection, due to a reduction of the dark respiration rate in combination with a reduction of the net photosynthesis rate at the first light level $\left( \pm 20 \mathrm{~J} \mathrm{~m}^{-2}\right.$ $\mathrm{s}^{-1} \mathrm{PAR}$ ). At both irradiance levels, stomatal conductance of 'Darwina' plants was more than halved by $G$. pallida (COND0 and COND1, respectively, Table 1), which limits $\mathrm{CO}_{2}$ concentration at the carboxylation site and thus reduces the net photosynthesis rate. Similar effects of $G$. pallida on 'Irene' plants were observed, but these were not significant (Table 1). At high irradiance, the net photosynthesis rate (PHOTHI, Table 1) was strongly reduced by $G$. pallida. This effect occurred on both cultivars, but was largest for the high nematode density on 'Darwina'. Transpiration rates were more strongly reduced by penetrating nematodes than the photosynthesis rates. This is reflected in a higher WUE (i.e. the ratio of photosynthesis rate to transpiration rate) of infected plants at all irradiance levels (Fig. 3).

The reduction of photosynthesis and transpiration rates by $G$. pallida may be caused by direct or indirect effects on stomatal closure. The response of stomatal conductance to decreasing ambient $\mathrm{CO}_{2}$ concentration was analysed (Fig. 4). At high $\mathrm{CO}_{2}$ concentrations, stomatal conductance of nematode infected plants was much lower than that of control plants. When the ambient $\mathrm{CO}_{2}$ concentration was gradually decreased, stomatal conductance of control plants increased strongly until the $\mathrm{CO}_{2}$ compensation point was reached at approximately $80 \mathrm{mg} \mathrm{m}^{-3}$. This reflects the negative feedback of $\mathrm{CO}_{2}$ supply for carboxylation processes on stomatal conductance (Goudriaan \& van Laar, 1978). Stomatal conductance of nematode infected plants remained low when ambient $\mathrm{CO}_{2}$-concentration decreased. This indicates a direct inhibition of stomatal opening by $G$. pallida.

To investigate whether $G$. pallida influenced carboxylation processes of leaves as well, the $\mathrm{CO}_{2}$ response of net photosynthesis at light saturation of control and infected plants was analysed (Fig. 5). Here photosynthesis rate is related to internal $\mathrm{CO}_{2}$ concentration to eliminate differences in stomatal resistance. The values

Table 1. Measured values of respiration rate in darkness (RD), transpiration rate in darkness (TRANSD), initial slope of light response (EFF), stomatal conductance in darkness and at $\pm 20 \mathrm{~J} \mathrm{~m}^{-2} \mathrm{~s}^{-1}$ PAR (COND0 and COND1, respectively) and net photosynthesis rate at high irradiance (PHOTHI), for plants infected with $G$. pallida and control plants of the potato cultivars 'Irene' and 'Darwina'. The $P$-value refers to the probability of false rejection of differences between infected and control plants

\begin{tabular}{|c|c|c|c|c|}
\hline \multirow[b]{3}{*}{ Variable } & \multicolumn{4}{|c|}{ Cultivar } \\
\hline & \multicolumn{2}{|c|}{ 'Irene' } & \multicolumn{2}{|c|}{ 'Darwina' } \\
\hline & Control & Infected & Control & Infected \\
\hline $\mathrm{RD}\left(\mu \mathrm{g} \mathrm{CO}_{2} \mathrm{~m}^{-2} \mathrm{~s}^{-1}\right)$ & 58.3 & $59.5(P=0.815)$ & 55.3 & $43.5(P=0.012)$ \\
\hline TRANSD $\left(\mathrm{mg} \mathrm{H}_{2} \mathrm{O} \mathrm{m}^{-2} \mathrm{~s}^{-1}\right)$ & 12.6 & $9.9(P=0.385)$ & 23.3 & $10.6(P=0.006)$ \\
\hline $\mathrm{EFF}\left(\mu \mathrm{g} \mathrm{CO} \mathrm{J}^{-1}\right)$ & 9.9 & $8.1(P=0.007)$ & 10.0 & $8.2(P=0.009)$ \\
\hline $\mathrm{CONDO}\left(\mathrm{mm}^{-1}\right)$ & 0.9 & $0.8(P=0.374)$ & 2.3 & $0.9(P=0.006)$ \\
\hline COND1 $\left(\mathrm{mm} \mathrm{s}^{-1}\right)$ & 3.6 & $1.5(P=0.006)$ & 2.5 & $1.0(P=0.004)$ \\
\hline РНОТНН $\left(\mu \mathrm{g} C \Theta_{2} m^{-2} s^{-1}\right)$ & 1123.5 & $810.9(P<0.001)$ & 1006.1 & $-570.0 \quad(P<0.001)$ \\
\hline
\end{tabular}


WUE $(x-10-3)$

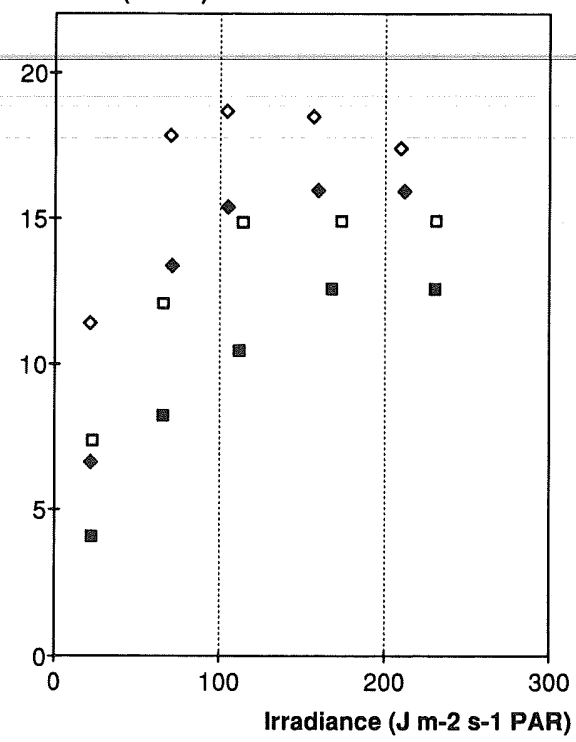

Figure 3. Response of water use efficiency (WUE, $\times 10^{-3}$ ) of leaves of potato cultivars 'Irene' and 'Darwina' to irradiance $\left(\mathrm{J} \mathrm{m}^{-2} \mathrm{~s}^{-1}\right), 3 \mathrm{~d}$ after inoculation with hatched juveniles of $G$. pallida, and of leaves of control plants. Symbols: $(\diamond)$ 'Darwina' infected with $G$. pallida; ( 'Darwina' control plants; ( $\square$ ) 'Irene' infected with G. pallida; (噃) 'Irene' control plants.

of PHOTHC and MC are given in Table 2. PHOTHC is strongly reduced by $G$. pallida. The internal $\mathrm{CO}_{2}$ concentration at which PHOTHC is reached is lower for infected plants than for control plants. The calculated mesophyll conductance for $\mathrm{CO}_{2}(\mathrm{MC})$ is significantly reduced by nematodes as well. This indicates either a

\section{COND (mm s-1)}

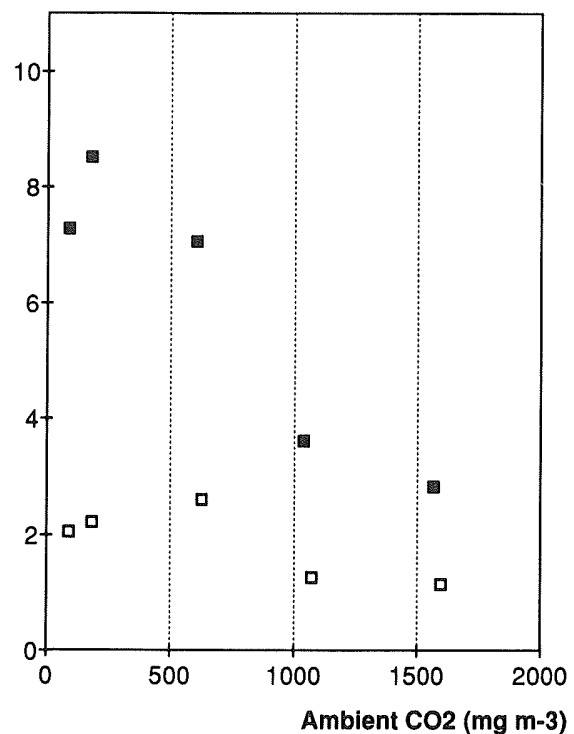

Figure 4. Response of stomatal conductance (COND, $\mathrm{mm} \mathrm{s}^{-1}$ ) to ambient $\mathrm{CO}_{2}$ concentration $\left(\mathrm{mg} \mathrm{m}^{-3}\right)$ at high irradiance of leaves of potato cultivar 'Darwina', $3 \mathrm{~d}$ after inoculation with hatched juveniles of $G$ pallida, and of leaves of control plants Symbols: (D) $G$. pallida-infected plants; (圈) control plants. non-uniform distribution- of stomatal closure over-the leaf, or a reduction of the carboxylation rate by $G$. pallida, which indirectly reduces stomatal aperture.

The water content of the measured leaves of infected plants tended to be higher than that of control plants for both cultivars, but this effect was not significant (Table 3).

\section{Nematode density in roots}

The estimated total number of juveniles present in the root system was 7160 for 'Irene', $12 \%$ of inoculum, and 18820 for 'Darwina', 7\% of inoculum (Table 3). A fraction of the juveniles had slightly swollen bodies, indicating that initiation of syncytia had occurred. The root system of 'Darwina' plants contained 3.3 times as many nematodes per gram dry root as the root system of 'Irene' plants. The number of recovered juveniles, expressed as a fraction of the total number inoculated, was low. Turner \& Stone (1984) observed that the recovery efficiency of early development stages of $G$. pallida from potato roots is lower than that of later stages. Therefore, it is likely that the actual number of juveniles penetrated in the roots was higher.

Table 2. Measured values of the net photosynthesis rate at high ambient $\mathrm{CO}_{2}$ concentration (PHOTHC) and of the initial slope of the $\mathrm{CO}_{2}$ response (MC), for plants infected with G. pallida and control plants of the potato cultivar 'Darwina'. The $P$-value refers to the probability of

false rejection of differences between infected and control plants

\begin{tabular}{lrr}
\hline Variable & Control & \multicolumn{1}{c}{ Infected } \\
\hline PHOTHC $\left(\mu \mathrm{g} \mathrm{CO}_{2} \mathrm{~m}^{-2} \mathrm{~s}^{-1}\right)$ & 1452.1 & $797.1(P<0.001)$ \\
$\mathrm{MC}\left(\mathrm{mm} \mathrm{s}^{-1}\right)$ & 4.6 & $3.6(P=0.041)$ \\
\hline
\end{tabular}

\section{Discussion}

Three days after inoculation second stage juveniles of $G$. pallida reduced leaf photosynthesis and transpiration rates of potato plants by an effect on stomatal resistance and an apparent independent effect on carboxylation processes. The latter effect is likely to be an artifact due to the erroneous assumption of uniform distribution of gas exchange over the leaf (Downton et al., 1988). Similar effects on photosynthesis have been observed after application of abscisic acid (ABA) to the transpiration flow through leaves of various plant species (Fischer, Raschke \& Stitt, 1986; Seemann \& Sharkey, 1987). Therefore, the process of penetration and initiation of syncytia by $G$. pallida in potato roots might increase the level of ABA in the leaves. Seemann \& Sharkey (1987) suggest that ABA production in leaves is the common link between any abiotic stress and reduction in photosynthesis rate. The results of my work suggest that this may also occur with $G$. pallida on potato. This is supported by Fatemy et al. (1985), who showed elevated ABA levels in leaves of potato plants, $47 \mathrm{~d}$ after planting in soil infested with cysts of $G$. rostochiensis. 
PHOT ( $\mu \mathrm{g} \mathrm{CO2} \mathrm{m-2} \mathrm{s-1)}$

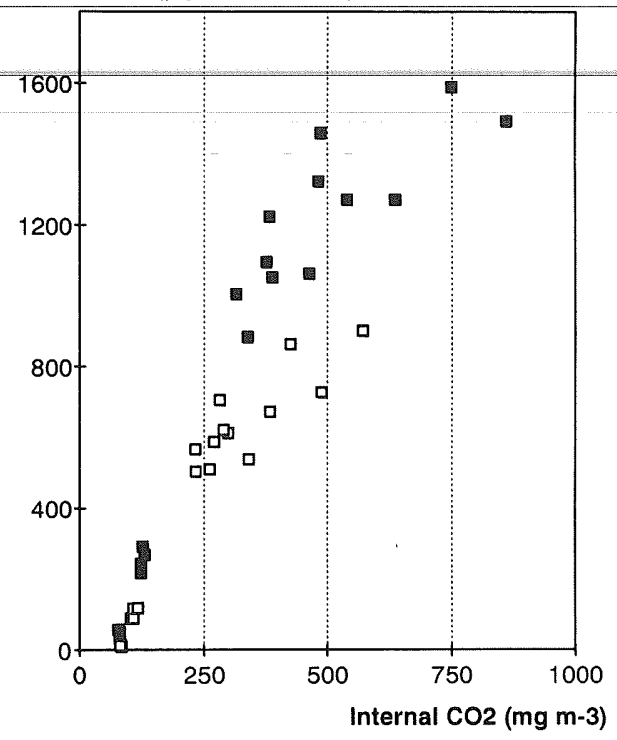

Figure 5. Response of net photosynthesis rate (PHOT; $\mu \mathrm{g} \mathrm{m}^{-2} \mathrm{~s}^{-1}$ ) to internal $\mathrm{CO}_{2}$ concentration $\left(\mathrm{mg} \mathrm{m}^{-3}\right)$ at high irradiance of leaves of potato cultivar 'Darwina', $3 \mathrm{~d}$ after inoculation with hatched juveniles of $G$. pallida, and of leaves of control plants. Symbols: ( $\square) G$. pallida-infected plants; (1) control plants.

The stomatal closure in nematode-infected plants may be explained by two possible mechanisms: induction of water stress in leaves due to reduced water uptake capacity of roots; or interference with production and transport of hormones synthesized in roots. The first mechanism is unlikely because the leaf water content of infected plants was not lower than that of infected plants. The second mechanism is supported by Gollan, Passioura \& Munns (1986), who showed that stomata close in response to a signal from the roots, independent of leaf water potential. The nature of the messenger substance, released by roots in drying soil, is not yet elucidated (Munns \& King, 1988; Zhang \& Davies, 1990). A reduction of photosynthesis rate not linked to water stress has been reported for several plants infected with nematode species from the families Heteroderidae and Meloidogynidae (e.g. Poskuta, Dropkin \& Nelson, 1986; Melakeberhan et al., 1985). Brueske \& Bergeson (1972) observed reduced cytokinin levels in root xylem sap of tomato plants infected with Meloidogyne incognita. Cytokinin may be the messenger for stomatal response to nematode infection.

It is unknown which actions of $G$. pallida specifically induce the closure of stomata. Rice, Stone \& Leadbeater (1987) observed that susceptible and resistant potato plants react similarly to penetration and movement of $G$. pallida juveniles through the root cortex. Within $48 \mathrm{~h}$ after inoculation of second stage juveniles on potato roots grown in Petri dishes, syncytial formation was initiated in roots of all clones tested. Subsequent development of syncytia was checked by resistance. In my work, the average temperature was approximately equal to the constant temperature of $20^{\circ} \mathrm{C}$ in the experiments of Rice et al. (1987). On the assumption that the period, necessary for movement of nematodes through the soil to the penetration site on the root surface, was 1-2d (Oostenbrink, 1950), nematodeplant interactions had advanced to the stage of syncytial formation at the time of the gas exchange measurements. This is confirmed by the recovery of slightly swollen second-stage juveniles from infected root systems. Therefore, stomatal closure must result from nematode actions just before or during formation of syncytia. Probably the disturbance of cell development just behind the root tip, which precedes syncytial formation (Seinhorst, 1986), interferes with the production of hormones which act as messengers for stomatal closure (Munns \& King, 1988).

This work demonstrated stomatal closure and reduction of leaf photosynthesis rate of potato plants due to root invasion by hatched second stage juveniles of $G$. pallida. The resistance of 'Darwina' did not prevent the nematode effects. This fits with field observations where resistant cultivars suffer as much damage as susceptible cultivars (Velema \& Boerma, 1987). However, in the natural situation with cyst inoculum stomatal function may be affected differently, because invasion of roots by $\mathrm{PCN}$ is dispersed over several weeks and the root density of second stage juveniles at each moment is much lower than that in my experiments. The response of stomatal function to nematode infection may also be influenced by the tolerance level of the cultivar (Fatemy et al., 1985). The consequences of these considerations for photosynthesis and stomatal functioning in relation to plant growth are reported by Schans \& Arntzen (1991).

Table 3. Water content (1.0 - dry weight/fresh weight) of measured leaves, immediately after gas exchange measurements, and root fresh and dry weights of plants infected with $G$. pallida and of control plants of the potato cultivars 'Irene' and 'Darwina' and the estimated number $( \pm \mathrm{SE} ; n=4)$ of nematodes in the root system of infected plants. The $P$-value refers to the probability of false rejection of differences between infected and control plants.

\begin{tabular}{|c|c|c|c|c|}
\hline \multirow[b]{3}{*}{ Variable } & \multicolumn{4}{|c|}{ Cultivar } \\
\hline & \multicolumn{2}{|c|}{ 'Irene' } & \multicolumn{2}{|c|}{ 'Darwina' } \\
\hline & Control & Infected & Control & Infected \\
\hline Leaf water content & 0.872 & $0.877(P=0.055)$ & 0.874 & $0.881(P=0.059)$ \\
\hline Root fresh weight (g) & 8.7 & $7.9 \quad(P=0.505)$ & 7.5 & $6.7 \quad(P=0.550)$ \\
\hline Root dry weight (g) & 1.6 & $1.5 \quad(P=0.580)$ & 1.4 & $1.2 \quad(P=0.440)$ \\
\hline Number of nematodes & & $7160 \pm 1930$ & & $18820 \pm 6790$ \\
\hline
\end{tabular}




\section{Acknowledgments}

Thanks are due to M. van Oijen, R. Rabbinge and A.F. van der Wal for comments on the manuscript. P. van Leeuwen assisted with the photosynthesis measurements.

\section{References}

Brown, E.B. (1969) Assessment of the damage caused to potatoes by the potato cyst eelworm, Heterodera rostochiensis Woll. Annals of Applied Biology, 63, 493-502.

Brown, E.B. (1983) The relationship of potato yield with and without nematicide to density of potato cyst nematodes, Globodera rostochiensis and G. pallida. Annals of applied Biology, 103, 471-476.

Brueske, C.H. \& Bergeson, G.B. (1972) Investigation of growth hormones in xylem exudate and root tissue of tomato infected with root-knot nematode. Journal of Experimental Botany, 23, 14-22.

Downton, W.J.S., Loveys, B.R. \& Grant, W.J.R. (1988) Stomatal closure fully accounts for the inhibition of photosynthesis by abscisic acid. New Phytologist, 108, 263-266.

Fatemy, F., Trinder, P.K.E., Wingfield, J.N. \& Evans, K. (1985) Effects of Globodera rostochiensis, water stress and exogenous abscisic acid on stomatal function and water use of Cara and Pentland Dell potato plants. Revue de Nématologie, 8, 249-255.

Fischer, E., Raschke, K. \& Stitt, M. (1986) Effects of abscisic acid on photosynthesis in whole leaves: changes in $\mathrm{CO}_{2}$ assimilation, levels of carbon-reduction-cycle intermediates, and activity of ribulose1,5-biphosphate carboxylase. Planta, 169, 536-545.

Gollan, T., Passioura, J.B. \& Munns, R. (1986) Soil water status affects the stomatal conductance of fully turgid wheat and sunflower leaves. Australian Journal of Plant Physiology, 13, 459-464.

Goudriaan, J. \& van Laar, H.H. (1978) Relations between leaf resistance, $\mathrm{CO}_{2}$-concentration and $\mathrm{CO}_{2}$-assimilation in maize, beans, lalang grass and sunflower. Photosynthetica, 12, 241-249.

Greco, N., Divito, M., Brandonisio, A., Giordano, I. \& De Marinis, G. (1982) The effect of Globodera pallida and G. rostochiensis on potato yield. Nematologica, 28, 379-386.

Kropff, M.J. (1987) Physiological effects of sulphur dioxide. 1. The effect of $\mathrm{SO}_{2}$ on photosynthesis and stomatal regulation of Vicia faba L. Plant, Cell and Environment, 10, 753-760.

Louwerse, W. \& van Oorschot, J.L.P. (1969) An assembly for routine measurements of photosynthesis, respiration and transpiration of intact plants under controlled conditioning. Photosynthetica, 3, 305-315.

Melakeberhan, H., Brooke, R.C., Webster, J.M. \& D'Auria, J.M. (1985) The influence of Meloidogyne incognita on the growth physiology and nutrient content of Phaseolus vulgaris. Physiological Plant Pathology, 26, 259-268.
Munns, R. \& King, R.W. (1988) Abscisic acid is not the only stomatal inhibitor in the transpiration stream of wheat plants. Plant Phystology, 88, 703-708.

Oostenbrink, M. (1950) Het aardappelaaltje (Heterodera rostochiensis Wollenweber), een gevaarlijke parasiet voor de eenzijdige aardappelcultuur. Ph.D. Thesis, Wageningen Agricultural University, The Netherlands.

Poskuta, J.W., Dropkin, V.H. \& Nelson, C.J. (1986) Photosynthesis, photorespiration and respiration of soybean after infection with root nematodes. Photosynthetica, 20, 405-410.

Rabbinge, R., Jorritsma, I.T.M. \& Schans, J. (1985) Damage components of powdery mildew in winter wheat. Netherlands Journal of Plant Pathology, 91, 235-247.

Rice, S.L., Stone, A.R. \& Leadbeater, B.S.C. (1987) Changes in cell structure in roots of resistant potatoes parasitized by potato cyst nematodes. 2. Potatoes with resistance derived from Solanum vernei. Physiological and Molecular Plant Pathology, 31, 1-14.

Schans, J. \& Arntzen, F.K. (1991) Reduction of leaf photosynthesis and transpiration of different potato cuiltivars by Globodera pallida in relation to plant growth. Netherlands Journal of Plant Pathology, in press.

Schulze, E.-D. (1986) Carbon dioxide and water vapour exchange in response to drought in the atmosphere and in the soil. Annual Review of Plant Physiology, 37, 247-274.

Seemann, J.R. \& Sharkey, T.D. (1987) The effect of abscisic acid and other inhibitors on photosynthetic capacity and the biochemistry of $\mathrm{CO}_{2}$ assimilation. Plant Physiology, 84, 696-700.

Seinhorst, J.W. (1965) The relation between nematode density and damage to plants. Nematologica, 11, 137-154.

Seinhorst, J.W. (1982) The relationship in field experiments between population density of Globodera rostochiensis before planting potatoes and yield of potatoes. Nematologica, 28, 277-284.

Seinhorst, J.W. (1986) The development of individuals and populations of cyst nematodes on plants. In Cyst Nematodes (eds F. Lamberti \& C.E. Taylor), pp. 101-117. Plenum Press, New York.

Trudgill, D.L. (1986) Yield losses caused by potato cyst nematodes: a review of the current position in Britain and prospects for improvements. Annals of Applied Biology, 108, 181-198.

Turner, S.J. \& Stone, A.R. (1984) Development of potato cyst nematodes in roots of resistant Solanum tuberosum ssp. andigena and $S$. vernei hybrids. Nematologica, 30, 324-332.

Velema, R. \& Boerma, M. (1987) Onderzoek naar het effect van de hoogte van de populatie van het aardappelcysteaaltje op de opbrengst van fabrieksaardappelen. In Onderzoek 1987, pp. 156158. Stichting Interprovinciaal Onderzoekcentrum voor de Akkerbouw op zand- en veenkoloniale grond in Middenoost- en Noordoost- Nederland, Assen, The Netherlands.

Zhang, J. \& Davies, W.J. (1990) Changes in the concentration of ABA in xylem sap as a function of changing soil water status can account for changes in leaf conductance and growth. Plant, Cell and Environment, 13, 277-285. 


\title{
Reduction of leaf photosynthesis and transpiration rates of po tato plants by second-stage juveniles of Globodera pallida
}

\author{
J. S $\subset$ HANS* Departments of Nematology and Theoretical Production Ecology, P.O. Box 8123, 6700 ES \\ Waz eningen, The Netherlands
}

Rec $\Longleftarrow i v e d ~ 23$ November 1990; received in revised form 11 February 1991; accepted for publication 18 February 1991

\begin{abstract}
Abs $=$ ract. Net photosynthesis and transpiration rates of pot to plants, grown in pots in the greenhouse, were mea sured at various light irradiances and ambient $\mathrm{CO}_{2}$ con $\Longleftarrow$ entrations, $3 \mathrm{~d}$ after inoculation with second stage juve niles of Globodera pallida. Gas exchange rates, bot in darkness and in light, and the initial light use effic iency were strongly reduced by nematodes. Stomatal conductance of infected plants was lower than that of control plants and showed little response to decreasing $\rightleftharpoons$ mbient $\mathrm{CO}_{2}$ concentration. The maximum internal $\mathrm{CO}=$ concentration of infected plants was lower than that of c ontrol plants. Globodera pallida reduced photosynthe $=$ is also by apparent non-stomatal effects.

T he effects of $G$. pallida on gas exchange rates are $\operatorname{sim}$ 1ar to the effects of abscisic acid in the transpiration stre am and of abiotic stresses in the root environment. Ap arently, there is a general response of plant roots to adV erse conditions. The reduction of photosynthesis ma $>$ be an important factor in yield reduction by potato cyst nematodes.

Key - words: Solanum tuberosum L.; Globodera pallida Stone; potato cys t nematodes; plant-parasite interaction; gas exchange; stomata; wate $\mathbf{r}$-use efficiency
\end{abstract}

\section{In - oduction}

Po ato cyst nematodes (PCN), Globodera rostochiensis (W - oll.) Skarbilovich and G. pallida Stone, cause serious yie $\mathrm{d}$ losses in regions where potatoes are grown frequ $\Longleftarrow$ ntly. Empirical relations between PCN density and yie $\mathbf{n}$ dloss, averaged over several experiments, have been est $\Longrightarrow$ blished by Seinhorst (1965) and Brown (1969). The pa ameter values in these relations vary strongly among ye rew rs, locations and cultivars (e.g. Greco et al., 1982; Se norst, 1982; Brown, 1983). This variation may be $\mathrm{du} \rightleftharpoons$ to effects of variable environmental factors on the ph siological processes that determine the behaviour of th $\rightleftharpoons$ potato - PCN system. These effects are not de $\leqslant$ cribed by the Seinhorst or the Brown equations.

Understanding of the effects of PCN on the physiolo 8 cal processes which determine the growth rate of a po $₹$ ato crop (e.g. photosynthesis, respiration and assimilat $\Longleftarrow$ partitioning) is a prerequisite for explanation of the

orrespondence and present address: J. Schans, Centre for Agrobiolog 1 acal Research (CABO), P.O.Box 14,6700 A A Wageningen, The $\mathrm{Ne} t$ Juerlands variation in yield reduction by PCN under field conditions. Several studies have been focused on effects of PCN on weight, dry matter content and mineral composition of plant organs and on plant water relations (reviewed by Trudgill, 1986). However, various disorders can cause the observed phenomena and the experiments do not explain which plant physiological processes are affected by PCN.

Disturbance of potato growth processes by PCN may occur during several phases of nematode development, in particular the invasion of roots by second-stage juveniles and the withdrawal of plant metabolites by following nematode stages. In this paper, the effects of penetration into roots and subsequent formation of syncytia by second stage juveniles of $G$. pallida on photosynthesis and transpiration rates of potato plants are investigated.

\section{Materials and methods}

Two experiments are described: one using the cultivar 'Irene' (susceptible) and nematode densities of 0 and 15 juveniles per gram of soil; and one using the cultivar 'Darwina' (with PCN resistance derived from Solanum vernei) and nematode densities of 0 and 65 juveniles per gram of soil.

\section{Plants, nematodes and inoculation}

Tubers (size: $28-35 \mathrm{~mm}$, with one sprout) of potato cultivars 'Irene' and 'Darwina' were surface-sterilized in a hypochlorite solution and planted in pots containing $4 \mathrm{~kg}$ of fertilized sandy loam soil to which $15 \%$ by weight of water was added $(\mathrm{pF}=2$; approximately field capacity). The pots were weighed and watered twice a day to keep soil moisture close to this level. The plants were grown in the glasshouse with 16 -h daylength. The minimum temperature was $14^{\circ} \mathrm{C}$ and the maximum varied between 20 and $26^{\circ} \mathrm{C}$.

Cysts of $G$. pallida pathotype $\mathrm{Pa} 2$ were placed in root exudate solution at $20^{\circ} \mathrm{C}$ after being soaked in water for $5 \mathrm{~d}$. The root exudate solution was changed each day and the emerged second-stage juveniles were collected and stored at $5^{\circ} \mathrm{C}$. Hatching continued over a period of $10 \mathrm{~d}$. Plants were inoculated 3 weeks after emergence. A suspension of the juveniles was injected into the soil using a veterinary syringe to approximate an even 
Acknowledgments

Thanks are due to M. van Oijen, R. Rabbinge and A.F. van der Wal for comments on the manuscript. P. van Leeuwen assisted with the photosynthesis measurements.

\section{References}

Brown, E.B. (1969) Assessment of the damage caused to potatoes by the potato cyst eelworm, Heterodera rostochiensis Woll. Annals of Applied Biology, 63, 493-502.

Brown, E.B. (1983) The relationship of potato yield with and without nematicide to density of potato cyst nematodes, Globodera rostochiensis and $G$. pallida. Annals of applied Biology, 103, 471-476.

Brueske, C.H. \& Bergeson, G.B. (1972) Investigation of growth hormones in xylem exudate and root tissue of tomato infected with root-knot nematode. Journal of Experimental Botany, 23, 14-22.

Downton, W.J.S., Loveys, B.R. \& Grant, W.J.R. (1988) Stomatal closure fully accounts for the inhibition of photosynthesis by abscisic acid. New Phytologist, 108, 263-266.

Fatemy, F., Trinder, P.K.E., Wingfield, J.N. \& Evans, K. (1985) Effects of Globodera rostochiensis, water stress and exogenous abscisic acid on stomatal function and water use of Cara and Pentland Dell potato plants. Revue de Nématologie, 8, 249-255.

Fischer, E., Raschke, K. \& Stitt, M. (1986) Effects of abscisic acid on photosynthesis in whole leaves: changes in $\mathrm{CO}_{2}$ assimilation, levels of carbon-reduction-cycle intermediates, and activity of ribulose1,5-biphosphate carboxylase. Planta, 169, 536-545.

Gollan, T., Passioura, J.B. \& Munns, R. (1986) Soil water status affects the stomatal conductance of fully turgid wheat and sunflower leaves. Australian Journal of Plant Physiology, 13, 459-464.

Goudriaan, J. \& van Laar, H.H. (1978) Relations between leaf resistance, $\mathrm{CO}_{2}$-concentration and $\mathrm{CO}_{2}$-assimilation in maize, beans, lalang grass and sunflower. Photosynthetica, 12, 241-249.

Greco, N., Divito, M., Brandonisio, A., Giordano, I. \& De Marinis, G. (1982) The effect of Globodera pallida and G. rostochiensis on potato yield. Nematologica, 28, 379-386.

Kropff, M.J. (1987) Physiological effects of sulphur dioxide. 1. The effect of $\mathrm{SO}_{2}$ on photosynthesis and stomatal regulation of Vicia faba L. Plant, Cell and Environment, 10, 753-760.

Louwerse, W. \& van Oorschot, J.L.P. (1969) An assembly for routine measurements of photosynthesis, respiration and transpiration of intact plants under controlled conditioning. Photosynthetica, 3, 305-315.

Melakeberhan, H., Brooke, R.C., Webster, J.M. \& D'Auria, J.M. (1985) The influence of Meloidogyne incognita on the growth, physiology and nutrient content of Phaseolus vulgaris. Physiological Plant Pathology, 26, 259-268.
Munns, R. \& King, R.W. (1988) Abscisic acid is not the only stomatal inhibitor in the transpiration stream of wheat plants. Plant Physiology, 88, 703-708.

Oostenbrink, M. (1950) Het aardappelaaltje (Heterodera rostochiensis Wollenweber), een gevaarlijke parasiet voor de eenzijdige aardappelcultuur. Ph.D. Thesis, Wageningen Agricultural University, The Netherlands.

Poskuta, J.W., Dropkin, V.H. \& Nelson, C.J. (1986) Photosynthesis, photorespiration and respiration of soybean after infection with root nematodes. Photosynthetica, 20, 405-410.

Rabbinge, R., Jorritsma, I.T.M. \& Schans, J. (1985) Damage components of powdery mildew in winter wheat. Netherlands Journal of Plant Pathology, 91, 235-247.

Rice, S.L., Stone, A.R. \& Leadbeater, B.S.C. (1987) Changes in cell structure in roots of resistant potatoes parasitized by potato cyst nematodes. 2. Potatoes with resistance derived from Solanum vernei. Physiological and Molecular Plant Pathology, 31, 1-14.

Schans, J. \& Arntzen, F.K. (1991) Reduction of leaf photosynthesis and transpiration of different potato cuiltivars by Globodera pallida in relation to plant growth. Netherlands Journal of Plant Pathology, in press.

Schulze, E.-D. (1986) Carbon dioxide and water vapour exchange in response to drought in the atmosphere and in the soil. Annual Review of Plant Physiology, 37, 247-274.

Seemann, J.R. \& Sharkey, T.D. (1987) The effect of abscisic acid and other inhibitors on photosynthetic capacity and the biochemistry of $\mathrm{CO}_{2}$ assimilation. Plant Physiology, 84, 696-700.

Seinhorst, J.W. (1965) The relation between nematode density and damage to plants. Nematologica, 11, 137-154.

Seinhorst, J.W. (1982) The relationship in field experiments between population density of Globodera rostochiensis before planting potatoes and yield of potatoes. Nematologica, 28, 277-284.

Seinhorst, J.W. (1986) The development of individuals and populations of cyst nematodes on plants. In Cyst Nematodes (eds F. Lamberti \& C.E. Taylor), pp. 101-117. Plenum Press, New York.

Trudgill, D.L. (1986) Yield losses caused by potato cyst nematodes: a review of the current position in Britain and prospects for improvements. Annals of Applied Biology, 108, 181-198.

Turner, S.J. \& Stone, A.R. (1984) Development of potato cyst nematodes in roots of resistant Solanum tuberosum ssp. andigena and $S$. vernei hybrids. Nematologica, 30, 324-332.

Velema, R. \& Boerma, M. (1987) Onderzoek naar het effect van de hoogte van de populatie van het aardappelcysteaaltje op de opbrengst van fabrieksaardappelen. In Onderzoek 1987, pp. 156158. Stichting Interprovinciaal Onderzoekcentrum voor de Akkerbouw op zand- en veenkoloniale grond in Middenoost- en Noordoost- Nederland, Assen, The Netherlands.

Zhang, J. \& Davies, W.J. (1990) Changes in the concentration of ABA in xylem sap as a function of changing soil water status can account for changes in leaf conductance and growth. Plant, Cell and Environment, 13, 277-285. 